\title{
Reading Tasks Analysis and Students' Perception: An Approach to Task-based Language Teaching
}

\author{
Doris Sukma \\ Universitas Negeri Padang, Padang, Indonesia \\ Yenni Rozimela \\ Universitas Negeri Padang, Padang, Indonesia \\ Ratmanida \\ Universitas Negeri Padang, Padang, Indonesia
}

\begin{abstract}
In task-based language teaching, task is classroom activity which emphasizes target language use and focuses on meaning. In teaching reading, the role of task is pivotal. It helps to provide context for students to read as reading activity in real-world. The concept of task is, however, complex in which it has some types and criteria. Different task may result in different effectiveness to teach reading. This study is aimed at exploring the use of different tasks to teach reading and seeking for students' perception about the use of those tasks. The data were obtained from a study involving 36 students of one of senior high schools in Padang. There were five different tasks designed based on task-like criteria. At the end of every meeting, the students were given a reading test to check their comprehension quality toward the text. A task perception questionnaire was then deployed to the students in order to find out their view toward the tasks. The data were analyzed and discussed descriptively. The result of analysis indicates that, in general, the five different tasks help the students to comprehend the text. However, based on the average score of reading test, drawing task appeared to be the most effective task due to some important reasons. The result of questionnaire also confirmed that, in all aspects, drawing task is positively viewed by most of the students.
\end{abstract}

Index Terms - task-based language teaching, TBLT, reading task, students' perception

\section{INTRODUCTION}

Generally speaking, asking students to read a text comprehensively in classroom is somewhat difficult. The students are usually lack of not only skills but also purposes to read and comprehend the text as reading in the real-world. In classroom context, there is a tendency that the students read without purpose (Willis and Willis, 2007). As the result, students are less interested toward reading activity, and comprehension of the text is unlikely to appear. To cope with this issue, there should be a proper method which can create purposeful reading situation in the classroom.

Task seems to be one of effective tools to get the students into a purposeful reading situation. Task provides context for the students to read which enables them to focus mainly on meaning of the text (Willis and Willis, 2007). In addition, as a meaning-focused activity, task can improve students' language skills (Ellis, 2003). Based on these arguments, it can be concluded that task can help the students to understand text better as it provides context to read like reading in realworld activity, and improves students' language skills since it focuses on meaning.

Some previous studies on task-based implementation have strengthened the importance of the task and have reported that it gives positive impact on students' language skills development and motivation (Danyan, 2016; Xuehua, 2016). As for reading skill, most of the studies reveal that task-based language teaching is effective to be used in teaching reading (Nahavandi, 2011; Chalak, 2015; Mubarok \& Sofiana, 2017; Irfan, 2017; Dollar, 2017). Hence, it can be inferred that the role of meaningful task in teaching reading is important since it positively affects students reading comprehension quality.

Despite of its effectiveness, there are still other flanks of task-based which remain uncultivated. One of them is the effectiveness of different tasks designed. Principally, it is not easy to design the task since the concept of it is, to some extent, complex. In TBLT, task has criteria; it focuses on meaning, it should be engaging, it should have clear outcome and priority of completion, and it reflects to real world activity (Willis and Willis, 2007; Ellis, 2003). In addition, it has many types which are classified based its nature (real-world and pedagogical task), the extent to which it can be used for any topics (listing, ordering, matching, comparing), and based on its starting point/source (personal knowledge and experience, problems, visual stimuli, spoken and written text, children activities, and integration of these starting points). Due to this complexity, different task designed will result in different effectiveness in teaching reading to the students.

This study is therefore aimed at exploring the effectiveness of different tasks used in teaching reading. To confirm the result of task effectiveness analysis, students' perception about those different tasks was also taken into consideration. 


\section{LITERATURE REVIEW}

\section{A. Task in TBLT Perspective}

Task-based language teaching (TBLT) is teaching method which primarily uses meaningful task to engage students in learning and as core unit planning and instruction to accomplish the goal of language teaching and learning (Richards and Theodore, 2001; Willis and Willis, 2007). As such, task is extremely important in TBLT. However, definitions of task which have been offered in literature are quite different in scope and formulation (Branden, 2006). Therefore, in the context of language teaching and learning, including in TBLT perspective, the nature of task should be settled.

Firstly, task is activity where the target language use by the students is necessary for a communicative purpose in order to achieve an outcome (Willis, 1996; Branden, 2006). In this sense, task does not mainly get the students to use target language form correctly since it will restrict their communicative language production ability. Instead, task is an activity which provides opportunity for the students to use target language to negotiate meaning; to clarify, to confirm, to agree/disagree, and etc.

Secondly, Ellis (2003) argues that task is a work plan which requires the students to process language pragmatically. It means that task is activity which insists the students to use target language as a resemblance to how people use the language in real life situation to interact with each other. In addition, Nunan (2004) argues that task is classroom work which involves students to comprehend, manipulate, produce, or interact in the target language. However, their attention should also focus on mobilizing grammatical knowledge to express meaning. Moreover, Branden (2006) also argues that form focused activity in task should not be excluded. Based on these arguments, it can be inferred that task should promote the students to use target language communicatively. However, attention to language form should not be neglected as it is also important. Thus, meaning and form are proportionally considered in TBLT. But, meaning focused-activity should come before form-focused activity.

To conclude, it can be said in nutshell that task is classroom activity which stimulates the students to use target language for interaction with each other. While meaning is primarily important to interact during task completion, the students should not ignore the importance of language form they display during target language production.

\section{B. Task's Characteristics}

In TBLT, task can be characterized in order to be easily acknowledged. Firstly, task should have the notion of engagement (Willis and Willis, 2007). In other words, task should have engaged the students. The notion of engagement is paramount. Without engagement or interest, the students are unlikely to focus on meaning or outcome of the task. It violates the nature of task itself whereas meaning is primary. Once the students engage with the task, then communicative language use occurs at ease. Accordingly, student-task engagement is pivotal.

The next characteristic is that task should enable the students to mainly focus on meaning and subsequently on form (Willis, 1996; Ellis, 2003; Nunan, 2004; Branden, 2006; Willis and Willis, 2007). An activity preceded by language forms introduction is less task-like one. Since communicative target use depends on vocabulary mastery, introduction on topic-related vocabulary is helpful for the students to complete the task. In addition, a gap should also be presented to motivate the students to use target language and focus and meaning. However, as Branden (2006) and Nunan (2004) argue, priority should be set between meaning-focused and form-focused activity. Meaningful language use implies the establishment of relevant form-meaning mapping (Branden, 2006). Accordingly, students should also pay attention (consciously or unconsciously) to language form while trying to focus on meaning.

Task is also said as activity with an outcome (Willis, 1996; Ellis, 2003; Willis and Willis, 2007). In this respect, the outcome should be communicative one or non-linguistic outcome (Willis, 1996). It means that the outcome should require the students to use target language as communicative as possible. Having students to write or remember a sentence to be presented with their pairs is less communicative outcome. On the other side, asking the students to have a complete survey or complete family member of their pairs is, to some extent, communicative outcome. Moreover, according to Ellis (2003), the outcome of the task also indicates to when the students are said to have completed the task. It is related to another criteria of the task namely priority of completion (Nunan, 2004; Willis and Willis, 2007). Thus, when the students have, for example, identified all family members, it can be said that the task has been completed and learning activity can be moved into the next stage.

The last but not least, task should relate to real-world activity or real-world process of how language is used (Ellis, 2003; Willis and Willis, 2007). In other words, task should be authentic which reflects to language use and to things people do in real life situation. According to Willis and Willis (2007), there are three levels of authenticity of the task namely meaning level, discourse level, and activity level. In meaning level, task gives students opportunity to engage in producing meanings which will be useful in the real world. The students will usually stretching language resource and use language which has been familiar to them to express the meaning. In discourse level, task enables the students to practicing kinds of discourse occurred in everyday life. At the activity level, task reflects to activity which easily occurs in real life situation.

On different place, Ellis (2003) argues that there are two levels of authenticity namely situational authenticity and interactional authenticity. Situational authenticity is the extent to which the task precisely corresponds to real world activity. However, some tasks may not completely reflects to real world activity but it manifests sort of relationship to real-word activity. This task is called to have interactional authenticity since it promotes students to use target language 
communicatively as in real-world situation. Based on the arguments, it can be seen that Willis and Willis' meaning level and discourse level is quite similar with Ellis' interactional authenticity since it gives the students opportunity to use language to interact. On the other hand, Willis' and Willis' activity level is similar with Ellis' situational authenticity. In nutshell, it can be assumed that these two experts share the same idea about task authenticity in TBLT.

\section{Task's Types}

Task can be distinguished based on its type. At first, task can be categorized into real-world task (target task) and pedagogical task (classroom task). Real-world task refers to the use of language beyond classroom or what the learners are supposed to be able to do in the real world. On the other hand, pedagogical tasks are those occur in the classroom or the things learners do with target language in the classroom which precisely resembles target task or simply provides communicative language use as in real-life situation (Nunan, 2004; Branden, 2006). Based on these definitions, it can be argued that target task is the task whereas the learners are expected to do and experience in the real-world. Pedagogical task, on the other side, is a task which either real-world task or approximate the real-world task sense in term of target language use.

Beside the extent to which the task resembles real-world activity, task can also be distinguished based on its appropriateness to be used for almost any topic or theme. According to Willis (1996) and Willis \& Willis (2007), there are some variety of tasks which can be adopted and used for any topic. It includes listing, ordering and sorting, comparing, problem solving, sharing personal experiences and creative task. These tasks involve cognitive process of the students. These topic-based tasks can potentially raise students' motivation when they are asked to suggest their own topic in the process of learning.

Moreover, task can be differentiated based on its starting point or main source. According to Willis (1996), there are some sources which can be used as starting point to design a task. It includes personal knowledge and experience, problems, visual stimuli, spoken and written text, children activities, and integration of these starting points. In this present study, starting point of task is written text, i.e. reading reading text since it dealt with teaching reading. In other words, the task is designed and adjusted based on reading text. It is also known as text-based task.

Text-based tasks require the students to process the text for meaning in order to achieve the goal of the task (Willis, 1996). It implies that the students have to comprehend the text to be able to complete the task. Through the present of the task, it engages the students in reading activity itself by listening or discussing the meaning of the text using communicative language. In different place, Willis and Willis (2007) argue that text-based tasks are designed to give the students purpose to read in the classroom context as reading in the real life situation. In the real life, people read for several purposeful reasons; either the topic is interesting, want to learn more about the topic, want to compare their opinion with text authors, or to simply satisfy their curiosity. Text-based tasks, in nature, are intended to bring these purposeful reasons to read to the students in the classroom context.

There are some tasks verities which can be designed based on text. It includes restoration task, jumbled task, memory challenge task, jigsaw task, and comparison task (Willis, 1996). On the other hand, Willis and Willis (2007) also propose other varieties of text-based task such as reading task, discussion task, prediction task, students as question master task, general knowledge task, corrupted text task, and recycle text task. All these tasks require the students to read the text comprehensively to subsequently come to task completion process. They all are useful in order to engage the students with reading text.

In the current study, some text-based tasks have been designed and some of them were adopted from Willis (1996) and Willis and Willis (2007). The tasks are presented in the following table.

TABLE 1

TEXT-BASED TASKS

\begin{tabular}{|l|l|l|}
\hline No & Task & Description \\
\hline 1 & Gap filling task (corrupted text) & Identifying words/phrases omitted from or added to a text \\
\hline 2 & $\begin{array}{l}\text { Making a simple timeline task (ordering } \\
\text { task) }\end{array}$ & Identifying correct order of events in the text to show to other pairs \\
\hline 3 & $\begin{array}{l}\text { Memory challenge tasks (cognitive } \\
\text { task) }\end{array}$ & $\begin{array}{l}\text { After a single brief exposure to the text, students list/describe/write about } \\
\text { what they can remember from the text to show to other pairs }\end{array}$ \\
\hline 4 & Drawing task (creative task) & $\begin{array}{l}\text { Drawing pictures which represent their comprehension of the text and } \\
\text { predicting the end of the story through pictures }\end{array}$ \\
\hline 5 & $\begin{array}{l}\text { Making a simple script task (creative } \\
\text { task) }\end{array}$ & $\begin{array}{l}\text { Create a simple drama script to be played based on the text. The ending of the } \\
\text { story is scripted differently as creative as possible from its original version }\end{array}$ \\
\hline
\end{tabular}

Based on the table above, it can be seen that there are five tasks which have been used to teach reading to senior high school students. Tasks like gap filling and memory challenge task were directly adopted from the experts while others (making simple script, drawing task, making simple script) were designed based on criteria of task-like activity and based on cognitive regulation of the students (creative task and ordering task).

\section{METHOD}

This is a descriptive study aimed to describe and analyzed the use of different tasks in teaching reading and students' perception about the tasks. This study is a part of an experimental research regarding task-based implementation. It was 
conducted in one of senior high schools in suburb area in Padang, Indonesia. The participants involved were 36 students. They were taught by using task-based language teaching (five different tasks for five meetings) and were given a reading test in each task at the end of the meeting. The test was in form of short answer response which covered some reading comprehension skills such as identifying text purpose, detail information, reference words, making inference, and guessing the meaning of unfamiliar words.

In addition to the test, the students were also given tasks perception questionnaire in order to see how they perceive different reading tasks which have been assigned to them. The questionnaire consists of 20 items. It was designed using Likert scale and based on four aspects which reflect to the criteria of a task-like activity in TBLT. The aspects are whether or not the task is interesting, has clear outcome, focuses on meaning, and provides opportunity for the students to use target language. The result of the questionnaire was then analyzed quantitatively.

\section{RESULTS}

\section{A. Reading Comprehension Score on Different Tasks}

There were five kinds of reading task designed based on the text that the students learnt with. The tasks were gap filling task, making a simple timeline task, memory challenge task, drawing task, and making a simple drama script task. At the end of every meeting, the students were given a reading test in form of short answer response to check their comprehension about the text they read. The students' reading comprehension scores of each task are presented below.

TABLE 2

DESCRIPTIVE STATISTICS ANALYSIS OF STUDENTS' READING COMPREHENSION SCORE UNDER DIFFERENT TASKS IMPLEMENTATION

\begin{tabular}{|c|l|c|c|c|c|c|}
\hline No & \multicolumn{1}{|c|}{ Tasks } & Mean & Max & Min & St.dev & Sum \\
\hline 1 & Gap Filling (Corrupted task) & 90 & 100 & 80 & 9.5 & 3240 \\
\hline 2 & Making Timeline (ordering task) & 88 & 100 & 70 & 11 & 3165 \\
\hline 3 & Memory Challenge (cognitive task) & 80 & 85 & 75 & 3 & 2880 \\
\hline 4 & Drawing (Creative task) & 95 & 100 & 70 & 9 & 3420 \\
\hline 5 & Making a simple Script (creative task) & 86 & 100 & 80 & 7 & 3100 \\
\hline
\end{tabular}

The table above illustrates the students' reading comprehension score under different tasks implementation. Based on the table, it can be seen that the highest mean score was in the implementation of drawing task (95). It is followed by gap filling task (90), Making simple timeline (88), making simple script (86), and memory challenge task (80). The highest score in all tasks but memory challenge task was 100. The minimum score was 80 in gap filling task and making a script task, 70 in making timeline task and drawing tasks, and 75 in memory challenge task. Based on the average score of each task, it can be underlined that drawing task helps the students to understand text easier.

\section{B. Students' Perception about Different Tasks}

A questionnaire intended to find out students' perception about the different tasks was deployed. The result of the questionnaire analysis is presented below.

1) Gap Filling Task

TABLE 3

The Result Of Students’ PeRCEPTION On GaP FiLling TAsK

\begin{tabular}{|l|l|l|l|l|l|}
\hline \multirow{2}{*}{ Aspect } & \multicolumn{3}{c|}{ Responds } & \multirow{2}{*}{$\mathrm{N}$} \\
\cline { 2 - 5 } & \multicolumn{1}{|c|}{ SA } & A & D & SD & \\
\hline Interesting & $9(25 \%)$ & $25(69 \%)$ & $2(6 \%)$ & $0(0 \%)$ & $36(100 \%)$ \\
\hline Has clear outcome & $13(36 \%)$ & $23(64 \%)$ & $0(0 \%)$ & $0(0 \%)$ & $36(100 \%)$ \\
\hline Focus on meaning & $15(42 \%)$ & $20(55 \%)$ & $1(3 \%)$ & $0(0 \%)$ & $36(100 \%)$ \\
\hline Provide target language use & $13(36 \%)$ & $22(61 \%)$ & $1(3 \%)$ & $0(0 \%)$ & $36(100 \%)$ \\
\hline
\end{tabular}

Based on the table above, it can be seen that most of the students have positive perception about filling gap task. An overwhelming proportion of the students agreed and strongly agreed that gap filling task is an interesting task (94\%), focuses on meaning $(97 \%)$, and provides opportunity to use target language $(97 \%)$. In term of task outcome, the students all together strongly agreed and agreed that gap filling task has clear outcome (100\%). However, there were two students $(6 \%)$ who considered that gap filling task is not interesting. Besides, there was one student $(3 \%)$ in each who disagreed that gap filling task is a meaning-focused task and provides opportunity to use target language.

2) Making a Simple Timeline Task

TABLE 4

The Result Of Students’ Perception On Making Simple Timeline

\begin{tabular}{|l|c|c|c|c|c|}
\hline \multirow{2}{*}{ Aspect } & \multicolumn{4}{c|}{ Responds } & \multirow{2}{*}{$\mathrm{N}$} \\
\cline { 2 - 6 } & $\mathrm{SA}$ & $\mathrm{A}$ & $\mathrm{D}$ & $\mathrm{SD}$ & $36(100 \%)$ \\
\hline Interesting & $12(33 \%)$ & $22(61 \%)$ & $2(6 \%)$ & $0(0 \%)$ & $36(100 \%)$ \\
\hline Has clear outcome & $18(50 \%)$ & $18(50 \%)$ & $0(0 \%)$ & $0(0 \%)$ & $36(100 \%)$ \\
\hline Focus on meaning & $11(30 \%)$ & $24(67 \%)$ & $1(3 \%)$ & $0(0 \%)$ & $36(0)$ \\
\hline Provide target language use & $16(44 \%)$ & $20(56 \%)$ & $0(0 \%)$ & $0(0 \%)$ & $36(100 \%)$ \\
\hline
\end{tabular}


In light of the table above, it can be seen that most of the students strongly agreed and agreed that making a simple timeline task was an interesting task (94\%) and focused on meaning (97\%). All of the students also strongly agreed and agreed that making a simple timeline has clear outcome (100\%) and provides opportunity for them to use target language (100\%). On the other way around, there were two students $(6 \%)$ who disagreed that making a simple script was interesting. Moreover, one student (3\%) admitted that making a simple timeline was not a completely meaningfocus activity.

3) Memory Challenge Task

TABLE 5

The Result Of Students’ Perception On Memory Challenge Task

\begin{tabular}{|l|c|c|c|c|c|}
\hline \multirow{2}{*}{ Aspect } & \multicolumn{4}{c|}{ Responds } & \multirow{2}{*}{$\mathrm{N}$} \\
\cline { 2 - 5 } & $\mathrm{SA}$ & $\mathrm{A}$ & $\mathrm{D}$ & $\mathrm{SD}$ & \\
\hline Interesting & $15(42 \%)$ & $20(55 \%)$ & $1(3 \%)$ & $0(0 \%)$ & $36(100 \%)$ \\
\hline Has clear outcome & $17(47 \%)$ & $17(47 \%)$ & $2(6 \%)$ & $0(0 \%)$ & $36(100 \%)$ \\
\hline Focus on meaning & $19(53 \%)$ & $17(47 \%)$ & $0(0 \%)$ & $0(0 \%)$ & $36(100 \%)$ \\
\hline Provide target language use & $13(36 \%)$ & $23(64 \%)$ & $0(0 \%)$ & $0(0 \%)$ & $36(100 \%)$ \\
\hline
\end{tabular}

The table above illustrates the students' perception toward memory challenge task. Based on the table, it can be seen that a lot of students strongly agreed and agreed that memory challenge task was interesting to them (97\%), and it has clear outcome (94\%). They were all strongly agreed and agreed that memory challenge task was meaning-focused activity (100\%) and gives them opportunity to practice using target language (100\%). However, there was a student (3\%) who disagreed that memory challenge was interesting. Likewise, there were two students $(6 \%)$ who disagreed, admitting that the outcome of memory challenge was not clear to them.

4) Making a Simple Drama Script

TABLE 6

The Result Of Students’ Perception On MAKING A Simple SCRIPT TASK

\begin{tabular}{|l|c|c|c|c|c|}
\hline \multirow{2}{*}{ Aspect } & \multicolumn{4}{c|}{ Responds } & \multirow{2}{*}{$\mathrm{N}$} \\
\cline { 2 - 5 } & $\mathrm{SA}$ & $\mathrm{A}$ & $\mathrm{D}$ & $\mathrm{SD}$ & \\
\hline Interesting & $12(34 \%)$ & $21(58 \%)$ & $3(8 \%)$ & $0(0 \%)$ & $36(100 \%)$ \\
\hline Has clear outcome & $13(36 \%)$ & $23(64 \%)$ & $0(0 \%)$ & $0(0 \%)$ & $36(100 \%)$ \\
\hline Focus on meaning & $11(30 \%)$ & $24(67 \%)$ & $1(3 \%)$ & $0(0 \%)$ & $36(100 \%)$ \\
\hline Provide target language use & $16(44 \%)$ & $19(53 \%)$ & $1(3 \%)$ & $0(0 \%)$ & $36(100 \%)$ \\
\hline
\end{tabular}

It can be seen from the table above that most of the students strongly agreed and agreed that making a simple script task was interesting (92\%), focused on meaning (97\%), and provides target language use (97\%). In term of task outcome, all of the students were strongly agreed and agreed that making a simple script task has a clear outcome $(100 \%)$. Alternately, there were three students (8\%) admitted that making a simple script was not an interesting task. Moreover, a student (3\%) disagreed with the statement saying that making a simple script provides opportunity to use target language.

5) Drawing Task

TABLE 7

THE RESUlt OF STUDENTS' PERCEPTION ON DRAWING TASK

\begin{tabular}{|l|c|c|c|c|c|}
\hline \multirow{2}{*}{ Aspect } & \multicolumn{4}{c|}{ Responds } & \multirow{2}{*}{$\mathrm{N}$} \\
\cline { 2 - 5 } & $\mathrm{SA}$ & $\mathrm{A}$ & $\mathrm{D}$ & $\mathrm{SD}$ & \\
\hline Interesting & $21(58 \%)$ & $14(39 \%)$ & $0(0 \%)$ & $1(3 \%)$ & $36(100 \%)$ \\
\hline Has clear outcome & $23(64 \%)$ & $12(33 \%)$ & $1(3 \%)$ & $0(0 \%)$ & $36(100 \%)$ \\
\hline Focuses on meaning & $22(61 \%)$ & $13(36 \%)$ & $1(3 \%)$ & $0(0 \%)$ & $36(100 \%)$ \\
\hline Provide target language use & $22(61 \%)$ & $13(36 \%)$ & $1(3 \%)$ & $0(0 \%)$ & $36(100 \%)$ \\
\hline
\end{tabular}

Based on the table above, it can be seen that most of the students (97\%) showed their strong agreement and agreement with each identified task aspect namely interesting task, task has clear outcome, task focuses on meaning, and task provides target language use. Conversely, there was a student (3\%) who strongly disagreed, saying that drawing task was not completely interesting task. Moreover, there was a student (3\%) who showed disagreement in each of the aspect namely the clarity of the outcome, meaning focused, and providing target language used.

\section{Discussion}

Based on some important findings above, the current study needs further discussion. To begin with, based on students' average score on each task, it was found that drawing task has the highest mean score (95) compared with every other task which had been implemented. In this respect, drawing task is said to inherently have one of task-like criteria namely real-world activity reflection (Gidoni \&Rajuan, 2018). In other words, drawing task is authentic. According to Ellis (2003:6), there are two kinds of authenticity level for every designed task in TBLT, i.e. situationally authentic and interactionally authentic. Situationally authentic refers to every task which is easily found in the realworld. Meanwhile, interactionally authentic is addressed to real-world activity which requires people to actively interact 
(using communicative language) during the activity. Drawing task is said to have these two levels of authenticity. It is one of the tasks which people do in real life situation (situationally authentic) and it encourages people to interact actively when it comes to drawing explanation and in the process of drawing itself. These authenticities lead into engagement, interest, and motivation of the students in learning.

On the other way around, the other four tasks which basically also help students in comprehending the text are less authentic compared to drawing task, especially gap filling task, and making a simple timeline. According to Willis and Willis (2007), gap filling task is useful in reading comprehension but it is an artificial task which focuses more on language form than the meaning of the language. The result of perception questionnaire confirms this statement since there were no more than half of the students (42\%) who strongly agreed that gap filling task get the students to focus on meaning. The more interactionally authentic task, that is making a script task, however, is not easily found and conducted by every individual in real life situation. It can also be seen from the result of questionnaire whereas only $36 \%$ of the students strongly agreed that this task has clear outcome. In other words, the students were not familiar with this task. Accordingly, in term of situational authenticity, making a simple script task is less authentic compared to drawing task.

The finding on students' questionnaire perception also confirmed and strengthened the authenticity of drawing task. A large proportion of the students $(61 \%)$ strongly agreed that drawing task focuses on meaning and provides opportunity to use target language (these all are manifestation of real-world activity). Real-world activity is usually interesting and focuses on meaning. In addition, authenticity of the task results in the clarity of task outcome. Since it is easily found and is conducted by many people in real life situation, $64 \%$ of the students (the highest percentage among the other tasks) strongly agreed that the outcome of drawing task is clear to them. However, based on the questionnaire, it was found that there was a student(3\%) who strongly disagreed or completely objected that drawing task is interesting whereas none of the students shares the same opinion on the other four tasks. The objection on drawing task can be caused by many factors. One of them is learning style preference or students' creativity level.

Secondly, drawing task is simply interesting (Altun, 2015; Elliot, 2007). It is also indicated by the result of task perception questionnaire. There were $58 \%$ of the students (the highest percentage among the other tasks) who strongly agreed that drawing task is an interesting task. Some possible explanations can be proposed. According to Gidoni \& Rajuan (2018), drawing task is interesting since it breaks the routine of reading comprehension classroom. Generally, in many reading classrooms, the students are asked to read and comprehend the text. Subsequently, they are given some comprehension questions to be answered related to the content of the text. This instructional teaching method resulted in boredom and motivation level of the students. Drawing task, which is authentic, appears to offer rejuvenation toward reading classroom activity. Hence, it attracts students' interest immediately.

In addition, drawing task is interesting since the students need less effort in order to conduct drawing activity than, for example, writing a summary of the text (Elliot, 2007). In its implementation, drawing task is proportionally a simple task. It requires the students to present their comprehension of the text in the papers in form of relevant pictures. Good and skillful readers appear to have more understanding and are likely to draw in a very detail way. On the other hand, poor readers are likely to have minimum comprehension of the text but they still can draw based on their own proportion of understanding. The other four tasks such as memory challenge tasks, making simple timeline and making a simple script tasks demand complex cognitive ability to get the tasks done. According to Willis (1996:80) memory challenge task requires the students to notice and remember things they have read in the text in fast reading. Thus, students with low cognitive ability will get difficulties in memorize text's details. It is proven by the highest score of each task whereas in memory challenge task, the students' highest score was 85 (the lowest among the other tasks). Likewise, making a simple script, which is basically a creative task, requires the students to incorporate other tasks such as listing, ordering, and matching to complete the task (Willis and Willis, 2007; Mao, 2012). Due to this complexity, these tasks turn into less interesting task. The result of perception questionnaire proves it since there were only $25 \%$ of the students (the lowest percentage among other tasks) who strongly agreed that gap filling task is an interesting task. Meanwhile, only $34 \%$ of the students strongly agreed that making a script task is an interesting to them.

Then, drawing task in the current study is interesting because it involves prediction task to predict the possible ending of the story. According to Willis and Willis (2007), integration of prediction and drawing task is lively and enjoyable activity. Prediction help the students in reading by providing context to read (students continue to think) and by guiding them into reading process. In addition, it prompts speculative discussion which ends in the intense use of target language communicatively. This once again disgorges into meaning focused activity. On the flipped side, in the other four tasks, prediction activity was not overtly involved. Communicative language use simply relies during the process of task completion itself. Accordingly, speculative discussion, which is interesting in nature, is not as lively as in drawing task. It can also be seen from the questionnaire whereas less than half $(50 \%)$ of the students strongly agreed that the other four tasks provide opportunity for them to use target language. It is significantly different with drawing task whereas $61 \%$ (more than half) of the students strongly agreed that it provides language use communicatively.

Lastly, drawing task actively engaged students (Elliot, 2007) since it focuses on meaning. Based on the questionnaire of perception, it is also found that $61 \%$ of the students strongly agreed that drawing task focuses on meaning. When the students draw, they have to visualize information they obtained from the text before translating it into series of picture. The information can be accepted either as literal meaning or elaborated or extended as personal interpretation. This 
process allows the students to be actively engaged with the text to find out the intended meaning of the author. It is somewhat different with the other four tasks, especially those who were less meaning-focused task and less authentic such as gap filling task.

\section{CONCLUSION}

This study has discussed the effectiveness of text-based tasks which have been used in teaching reading comprehension to senior high school students. Text-based tasks require the students to read the text before coming to task completion. This type of task is extremely helpful in order to engage the students with their reading text. Based on this study, it was revealed that the most effective task which helps to promote students' reading comprehension quality is drawing task. Compared to every other task which has been implemented, drawing task fulfills task-like criteria at the most. In other words, drawing task is the most authentic, interesting, and engaging task. In addition, the outcome of drawing task is familiar and very clear to the students. It implies that in designing the task, especially in TBLT practice, teachers should think over the criteria of task-like activity, i.e. interesting, has clear outcome, focuses on meaning, and reflects to real-world activity. Moreover, task which closely resembles real-world activity is essential. However, when it is difficult to closely resemble and bring real-world task into classroom activity, task which promotes interaction or communicative target language use in the classroom can also be used as an alternative for language teachers to enhance their students' language development.

\section{ACKNOWLEDGEMENTS}

I would like to thank Prof. Dra. Yenni Rozimela, M.Ed., Ph. D and Dr. Ratmanida, M.Ed. TEFL who have helped me in writing this article, given a great deal of time and offered critical and constructive comments for the purpose of improvement.

\section{REFERENCES}

[1] Altun, Mustafa. (2015). The Use of Drawing in Language Teaching and Learning. Journal of Educational and Instructional Studies in the World 5.4, 91-93.

[2] Chalak, Azizeh. (2015). The Effect of Task-Based Instruction on Reading Comprehension of Iranian EFL Learners. Applied Research on English Language 4.1, 19-29.

[3] Danyan, Huang. (2016). A Study on the Application of Task-based Language Teaching Method in a Comprehensive English Class in China. Journal of Language Teaching and Research 7.1, 118-127.

[4] Dollar, Keşli, Y. (2017). Effects of Task-based Instruction on Reading Comprehension of Turkish EFL Learners. International Journal of English Language Teaching 5.3, 1-15.

[5] Elliot, J. (2007, January 4). Summarizing with drawings: a reading-comprehension strategy. http://www.nsta.org/publications/news/story.aspx?id=53158 (accessed 15/10/2019).

[6] Ellis, Rod. (2003). Task-based Language Learning and Teaching. New York: Oxford University Press.

[7] Gidoni, Yasmin, \& Rajuan, Maureen. (2018). The Use of Drawing Task as Creative Strategy for Pupils in the English Area as Foreign Language (EFL) Classroom. Journal of second language teaching and research 6.1, 5-19.

[8] Irfan, Irfan. (2017). The Effect of Task-based Language Teaching on Students' Reading Comprehension. English Education Journal 8.1, 113-126.

[9] Mao, Zan. (2012). The Application of Task-based Language Teaching to English Reading Classroom. Theory and Practice in Language Studies 2.11, 2430-2438.

[10] Mubarok, Husni \& Sofiana, Nina. (2017). The Effect of Task-Based Language Learning and Learning Styles on the Students' Reading Ability. Journal of Language and Literature 12.1, 19-30.

[11] Nahavandi, Naemeh. (2016). The Effect of Task-based Activities on EFL Learner's Reading Comprehension. The Journal of Advances in Language and Literacy Studies 2.1, 56-69.

[12] Nunan, David. (2004). Task Based Language Teaching. New York: Cambridge University Press.

[13] Richards, Jack, C. \& Rodgers, S. Theodore. (2001). Methods and Methods in Language Teaching (2nd). Cambridge: Cambridge University Press

[14] Van den Branden, K. (2006). Introduction: Task-based Language Teaching in a Nutshell. In Van den Branden, K. (ed.), TaskBased Language Education: From Theory to Practice. Cambridge: Cambridge University Press, 1-18.

[15] Willis, Dave and Willis, Jane. (2007). Doing Task-Based Teaching. New York: Oxford University Press.

[16] Willis, Jane. (1996). A Framework for Task-based Learning. Edinburgh: Addison Wesley Longman Limited.

[17] Xuehua, Wu et al. (2016). Implementing Task-based Instruction in ESP Class-An Empirical Study in Marine Engineering English. Journal of Language Teaching and Research 7.5, 936-945. 


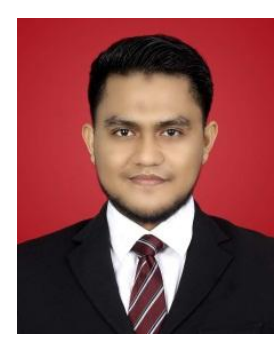

Doris Sukma was born in Pekanbaru, Indonesia, in 1992. He received his first degree in English language teaching from Universitas Riau, Pekanbaru, Indonesia in 2010. He is currently a graduate student of English Language Teaching Department in Universitas Negeri Padang, Indonesia.

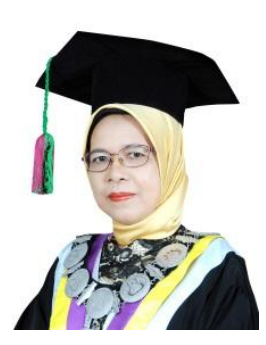

Yenni Rozimela was born in Balai Gurah Agam, Indonesia, in 1962. She received her Master's and Ph.D degree in English language teaching from University of Melbourne, Australia, in 1995 and 2005.

She is a Professor in English language teaching and currently working as a lecturer in English Language Teaching Department in Universitas Negeri Padang. She is also the current Director of Graduate Program in Universitas Negeri Padang, Indonesia.

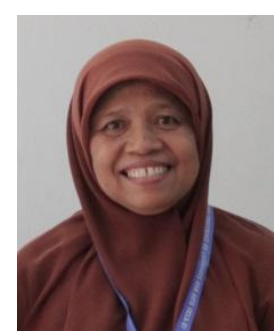

Ratmanida holds a doctorate degree in English language teaching from Universitas Pendidikan Indonesia in Bandung. She is currently working as a lecturer in English Language Teaching Department in Universitas Negeri Padang. Her research areas of interest are English language teaching and TEFL. 